retrospective analysis there does not seem to have been any protection to patients reportedly using chemoprophylaxis.

Although the authors acknowledge the poor quality of their data, I suggest that these data are not complete or accurate enough for testing or confirming their hypothesis.

Hospital for Tropical Diseases Travel Clinic,

R H BEHRENS

London W1P 9LE

1 Lewis SJ, Davidson RN, Ross EJ, Hall AP. Severity of imported falciparum malaria: effect of taking antimalarial prophylaxis. falciparum malaria: effect of taking an

2 Centers for Disease Control. Malaria surveillance summaries. Atlanta: CDC, $1981-8$

EDrror,-Stephen J Lewis and colleagues neglect the importance of immunity in their analysis of the associations of severe and mild malaria with antimalarial chemoprophylaxis. ${ }^{1}$ They state that "Africans living in Africa and those living in the United Kingdom were combined to form one group as they appeared to have the same proportions of severe versus mild malaria." This statement is not compatible with my clinical experience. Immunity rather than drug prophylaxis is the best predictor of whether a patient gets severe or mild malaria, and an individual's previous exposure to malaria is more significant than his or her ethnic group alone.

Most textbooks of tropical medicine discuss malaria in immune and non-immune patients in separate sections. It is not valid to combine data from a study of immune and non-immune subjects and draw conclusions about the time to presentation or association with sex or indeed the effect of prophylaxis on the severity of malaria generally.

An impressive protective effect of drug prophylaxis was found in the white ethnic group. Because in the African patients there is the confounding factor of acquired immunity the study should have been restricted to the non-immune white group alone.

Central Hospital,

PAUL ANTHONY REEVE

Private Mail Bag 013

Port Vila,

Vanuatu

1 Lewis SJ, Davidson RN, Ross EJ, Hall AP. Severity of imported falciparum malaria: effect of taking antimalarial prophylaxis. $B M 7$ 1992;305:741-3. (26 September.)

\section{An alternative to QALYs: saved young life equivalent (SAVE)}

EDITOR,-Erik Nord correctly describes public resentment against the use of quality adjusted life years (QALYs) for determining priorities in health care programmes, particularly regarding the assignment of a lower value to individuals with a disability.' He also makes the point that the QALY emphasises the degree of health improvement and often disregards the starting and end points. He suggests that health care outcomes may alternatively or additionally be measured relative to a unit of saving a young life (SAVE).

This unit, however, is not adequately defined. Differing clinical situations such as saving a neonate with intensive care, saving a nearly drowned infant, and resuscitating a multiply injured teenager would all be equivalent to one SAVE unit. The relative value or equivalence number given to other interventions and outcomes could consequently vary depending on which definition of SAVE units the judges used for calibration. Attitude and knowledge may also vary considerably within and between groups of judges asked to compare health care outcomes, which would introduce bias. At best the SAVE unit represents a possible proxy measurement of relative public attitude towards health problems; but as judges' responses would depend on thei own knowledge and experiences they would be a jury rather than judges. It is the managers and health care workers who should have the responsibility to be the judges, as only they have the collective knowledge and expertise of making explicit decisions regarding the appropriate use of finite resources.

Rational choices between health care programmes can be achieved only by procuring accurate, timely, and comparable data. This goa can be realised by adopting a unified language of health, which the NHS is developing with the Read coding system. The use of this coding thesaurus to capture the complete electronic medical records will allow accurate analysis of case mix and health care outcomes. Using this common, defined language of health - not crude proxy comparative units-will enable both managers and clinicians to evaluate the quality and cost effectiveness of health care provision.

\section{Wootton Surger}

King's Lynn,

Nord E. An alternative to QALYs: the saved young life equivalent (SAVE). BM7 1992;305:875-7. (10 October.)

EDrToR,-Attempts to quantify the benefits of healthcare interventions are increasingly important in today's economic climate. Erik Nord's suggestion of the "saved young life equivalent" (SAVE)' as the standard against which possible benefits are compared does, however, raise several issues. He states that saving the life of a young person and restoring him or her to full health is used as the chosen unit of measurement, as "most people will probably regard it as the maximum benefit that a single individual can obtain." This (if true) is presumably because a healthy young person is perceived to have maximum potential in terms of number of years remaining to work and contribute to the economy and society. This concept automatically disadvantages patients who are older or disabled (mentally or physically), who by definition can never by any intervention gain one SAVE. Those interventions required by olde people in a time of limited resources would, it seems, be authorised only if they were cheap.

The whole basis of the SAVE hypothesis is that societal attitudes determine medical priorities. Though the views of the population need to be taken into account, there is a distinct danger that this procedure might enshrine into the funding system false views about therapy options and their chances of success. If those polled are given information about the procedures they are assessing before they make a decision whose version of the truth will they receive? We are all aware of the strength of opinions held by opposing camps on the merits of many (even well established) procedures. Society's prejudices are bound to influence people's responses. As a recent King's Fund repor stated, "Personal preferences about the form one's life should take do not yield social judgments about how lives in general are to be treated.",

Even if rating scales are accepted as a tool of assessment they are, as Nord admits, unstandardised. It has recently been found that the efficiency with which any scaling procedure can capture and represent personal preferences for health care is largely unknown. ${ }^{3}$ If median results are used, a suggested by Nord, then the views of (even large) minorities would be underrepresented. The recen pre-election surveys highlight the difficulty of accurately assessing popular opinion. Answers given in isolation are often different from those given when the consequences of the decision are immediately relevant.

The rationing system within health care is becoming more explicit, and tools for assessing public opinion are needed. I am not convinced that the SAVE system is what is required.

S R GLICHER

Cheadle Medical Practice,

Cheadle,

Cheshire SK8 1 BH

Nord E. An alternative to QALYs: the saved young life equivalent (SAVE). BMf 1992;305:875-7. (10 October.)

King's Fund. Cost and choice in healthcare. London: King Edward's Hospital Fund for London, 1988. (Ch 7.)

Kind $P$. The design and construction of quality of life measures. York: York University Centre for Health Economics, 1991 (Discussion paper 43. .

EDITOR,-The value of saving a young life as a unit of measurement is not easily understandable in the context of Erik Nord's article. 'It is understandable only in terms of the longer life expectancy provided to one saved younger. Such benefit in life years has a pivotal function in allocation of QALYs, a function that has been criticised as agist. ${ }^{2}$ The age of the young life saved is unstated, begging the question whether a 30 year old ought to be allocated the same value of one SAVE as a 10 year old. Perhaps the maximum social benefit lies in preventing one abortion. Nord criticises QALYs for defining the value of health improvements as numerical health state values but recognises that SAVE would rely on the support of a similar mathematical model in order to estimate values for a vast number of outcomes not valued directly by the public.

In appealing to the public it is unclear how different outcomes are to be compared with one SAVE by relying on social values. The example given is that more value could be placed on outcomes entailing less benefit to more severely affected people who would be discriminated against by QALYs. This flexibility results from appealing to the principle of equality, such that everyone is entitled to care and patients worse affected are as entitled as those less affected. (Nord's suggestion that they would be more entitled simply introduces further injustice.) If we accept the equality principle, which is criticised as lacking in the QALY procedure, ${ }^{2}$ we must accept that everyone is entitled to equal care irrespective of age, sex, race, and other qualifiers.

The benefit of having one's life saved is unarguable, but the value of life to an individual does not necessarily diminish with age. It does, however, diminish in societal terms, which look to productivity and the "fair innings" argument. ${ }^{3}$ Subscribing to such social values may discount significant services to elderly people, and the adoption of one SAVE as a unit of measurement could dangerously entrench agism

Directorate of Medicine for the Elderly,

GWEN SAYERS

Barts NHS Trust,

London E9 $6 \mathrm{~B}$

1 Nord E. An alternative to QALYs: the saved young life equivalent (SAVE). BMf 1992;305:875-7. (10 October.)

2 Harris J. More and better justice. In: Bell JM, Mendus S, eds. Philosophy and medical welfare. Cambridge: Cambridge Philosophy and medical we
University Press, 1988: 75-96.

3 Lockwood M. Quality of life and resource allocation. In: Bell JM, Mendus S, eds. Philosophy and medical welfare. Cambridge: Cambridge University Press, 1988:33-55.

AUTHOR'S REPLY,-The SAVE procedure allows evaluators of health care to take account not only of the amount of health produced but also of any distributional consideration they might find relevant. Most people seem to consider prolonging the life of a young person more important than prolonging the life of an old person.' Before implementing the SAVE procedure in a health programme evaluation society would have to decide more specifically to what extent age should count. Unlike in the conventional QALY procedure it need not be very much. For instance, we need not 
discriminate according to age in providing care to people who are chronically ill. However, as long as age is viewed to some extent as a relevant factor the unit of measurement (the SAVE) needs to be specified in terms of age

The specification of "a young life" would depend on how strongly society wishes to discriminate between young people. This is not for me to decide. The point is that the SAVE procedure is not inherently agist. By deciding equivalence numbers (or the inverse, priority weights) for different age groups in specific contexts, and by explicitly deciding to what degree the social value of an outcome increases with its duration, society can make the SAVE procedure precisely as agist or non-agist as it wishes.

The choice of "saving a young life" as a unit of measurement is based on consideration of medical benefit (quantity of well life produced) only. It has nothing to do with contribution to the economy. The SAVE approach consists in valuing outcomes-that is, movements from different levels of dysfunction to higher levels. These valuations should be elicited independently of diagnoses and procedures. They need to be combined with doctors' assessments of the effects of procedures to obtain the value of the procedures. The SAVE approach does not include scaling of personal preferences for health care. It is concerned with equivalence of numbers of patients.

I don't believe that any numerical measure of benefit can be free of limitations. Hence I suggest the SAVE procedure only as an aid to priority setting.

National Institute of Public Health,

ERIK NORD

Geitmyrsveien 75

0462 Oslo,

Norway

1 Lewis PA, Charny M. Which of two individuals do you trea when only their ages are different and you can't treat both? fMed Ethics 1989;15:28-32.

\section{Balloon dilatation of heart valves}

EDrToR,-We agree with Roger Hall and Richard Kirk's conclusions regarding the poor overall results of balloon dilatation in aortic valve stenosis and share their preference for aortic valve replacement in most cases.' With regard to mitral valvuloplasty, however, the authors' statement that "no randomised comparisons of valvuloplasty and surgery have been made" is incorrect. At least three published studies have compared percutaneous balloon mitral valvuloplasty with surgery for mitral stenosis: two performed by our group working with fellow investigators in Hyderabad, India, and one from South Africa. ${ }^{2-4}$

Our two studies were randomised prospective trials, with the data analysed by investigators blinded to the treatment and the time of evaluation. The first study compared percutaneous balloon mitral valvuloplasty with closed mitral commissurotomy ${ }^{2}$; the second compared it with open mitral commissurotomy. ${ }^{3}$ Both studies included cardiac catheterisation before the study and one week, six months, and three years after the procedure as well as echocardiography and stress testing. The results to six months have been reported, and we found no significant differences in efficacy or safety between the treatment groups.

These trials enrolled patients with pliable valve leaflets, fairly modest calcification, and an absence of factors that would favour surgery, such as appreciable mitral regurgitation or severe subvalvular disease. They did, however, include some patients with severe pulmonary hypertension, who might benefit from avoiding thoracotomy. Thus, although we share Hall and Kirk's concerns that the advantages of balloon valvuloplasty are "mean- ingless unless the safety and efficacy of dilatation compare favourably with those of conventional surgery," we believe that as linear follow up of these patients is published there will be ample data to support the use of balloon valvuloplasty for well selected patients with mitral valve stenosis.

Z G TURI B S FROMM

Wayne State University,

Detroit,

MI 48201,

USA

1 Hall R, Kirk R. Balloon dilatation of heart valves. BMF 1992 305:487-8. (29 August.)

2 Turi ZG, Reyes VP, Raju BS, Raju AR, Kumar DN, Rajagopa $\mathrm{P}$, et al. Percutaneous balloon versus surgical closed commissurotomy for mitral stenosis. A prospective randomized trial. surotomy for mitral stenosis.

3 Reyes VP, Raju BS, Turi ZG, Rajagopal P, Stephenson L, Meht PM, et al. Percutaneous balloon vs open surgical commisPM, et al. Percutaneous balloon vs open surgical commis-
surotomy for mitral stenosis: a randomized trial. Circulation 1990;82(suppl III): 545 .

4 Patel JJ, Shama D, Mitha AS, Blyth D, Hassen F, Le Roux BT Patel JJ, Shama D, Mitha AS, Blyth D, Hassen F, Le Roux BT,
et al. Balloon valvuloplasty versus closed commissurotomy fo pliable mitral stenosis: a prospective hemodynamic study. f Am Coll Cardiol 1991;18:1318-22.

\section{Cerebral oedema in diabetic ketoacidosis}

EDITOR,-In their editorial on cerebral oedema in diabetic ketoacidosis' Peter Hammond and Simon Wallis refer to the sodium ion-hydrogen ion exchanger hypothesis.? They state that in models of diabetic ketoacidosis "cerebral pH is not greatly decreased, so weak organic acids probably do not enter brain cells to cause cytoplasmic acidification." This statement contains two errors.

Firstly, no studies that I am aware of have examined cerebral $\mathrm{pH}$ in diabetic ketoacidosis. If the authors are referring to the animal studies of Arieff and Kleeman, ${ }^{3+}$ these have already been dismissed as more relevant to the non-ketotic hyperosmolar state and of questionable relevance to diabetic ketoacidosis with its prominent organic acidosis. Of greater concern is the authors' implication that weak organic acids would not ente "brain cells." Cellular acidification by weak organic acids does occur at clinically relevan $\mathrm{pH}$ values ( $\mathrm{pH} 6 \cdot 9-7 \cdot 4)$. This is because the process depends not on a tissue specific membrane carrier mechanism but, rather, on simple diffusion of the protonated form of the weak organic acid across the lipid bilayer. ${ }^{56}$ Cultured glial cell lines undergo cytoplasmic acidification on exposure to weak organic acids and then swell in a manne totally consistent with activation of the sodium ionhydrogen ion exchanger.' Sodium ion-hydrogen ion exchanger activity is well documented in mammalian neuronal cells $\mathrm{s}^{\wedge}$ and can be expected to behave in a qualitatively similar manner.

Once basic properties of the sodium ionhydrogen ion exchanger are appreciated it is diffcult to see how the exchanger could be prevented from producing cerebral oedema in the metabolic setting of diabetic ketoacidosis. Indeed, evidence suggests that cerebral oedema may occur routinely in uncomplicated diabetic ketoacidosis." What is not explained is why only a minority of children develop the extreme, catastrophic form of cerebral oedema. One explanation would be variations in those details of treatment that could act through the sodium ion-hydrogen ion exchanger mechanism (for example, rapid correction of extracellular $\mathrm{pH}$ or excessive delivery of insulin or sodium). It is equally plausible, however, that the basis of the observed clinical variation will be found in a functional polymorphism of either the exchanger itself or factors controlling its activity.

The sodium ion-hydrogen ion exchanger model for cerebral oedema in diabetic ketoacidosi remains remarkably consistent with the available evidence. It should be of interest to those wishing to explore this clinical condition through use of an animal model.

Faculty of Health Sciences,

McMaster University,

Hamilton,

Ontario,

Canada

Hammond $\mathrm{P}$, Wallis $\mathrm{S}$. Cerebral oedema in diabetic ketoacidosis. BM7 1992:305:203-4 (25 July.)

VanderMeulen JA, Klip A, Grinstein S. Possible mechanism for cerebral oedema in diabetic ketoacidosis. Lancet 1987;ii:306-7.

Arieff AI, Kleeman CR. Studies on mechanisms of cerebral edema in diabetic comas. $f$ Clin Invest 1973;52:571-83.

4 Arieff AI, Kleeman CR. Cerebral edema in diabetic comas. II. Effects of hyperosmolality, hyperglycemia and insulin in diabetic rabbits. 9 Clin Endocrinol Metab 1974;38:1057-67.

5 Roos A, Boron WF. Intracellular pH. Physiol Rev 1981;61: 296-434

6 Grinstein S, Goetz JD, Furuya W, Rothstein A. Gelfand EW Amiloride sensitive $\mathrm{Na}+\mathrm{H}+$ 'xchange in platelets and leukocytes: detection by electronic cell sorting. Am $\mathcal{F}$ Physiol 1984; 247: C293-8.

7 Jakubovicz DE, Grinstein S, Klip A. Cell swelling following recovery from acidification in $\mathrm{C} 6$ glioma cells: an in vitro model of postischemic brain edema. Brain Res 1987;435:138-46.

8 Jean T, Frelin C, Vigne P, Barbry P, Lazdunski M. Biochemical properties of the $\mathrm{Na}+/ \mathrm{H}+$ exchange system in rat brain synaptosomes. F Biol Chem 1985;260:9678-84.

9 Krane EJ, Rockoff MA, Wallman JK, Wolsdorf JI. Subclinical brain swelling in children during treatment of diabetic ketoacidosis. N Engl f Med 1985;312:1147-51.

\section{Code of practice for over the counter products}

EDITOR,-A new acaricide--Sargeant's House Dust Mite Patrol - that is claimed to reduce levels of house dust mites has recently been launched. The manufacturers provide data on its ability to reduce house dust mite levels but no data to show that it helps patients with asthma. Correspondence from the manufacturers indicates that they are able to provide reasonable data on toxicity to humans but have no data on clinical efficacy. One of their promotional posters contains this misleading statement: "As an allergy sufferer you can benefit from a reduced frequency and severity of attacks by establishing a preventative programme to significantly reduce the effects of House Dust Mite population in your home."

I am concerned that the manufacturers have done no clinical trials to show that this particular formulation has any clinical benefit. Many previous acaricides have failed to result in clinical benefit despite reducing house dust mite levels (and therefore airborne allergen levels) substantially.

It seems to me that a code of practice needs to be applied to such substances, particularly as they are sold without prescription. I am aware that this substance is not ingested by patients, but it seems inappropriate for any product to be launched so aggressively without any evidence of clinical benefit. Pharmaceutical companies have to go to enormous lengths to produce data on efficacy before their products are released on to the market; when an over the counter preparation claims to reduce asthma some assessment of the regulation of such products is surely needed.

JON G AYRES

Department of Respiratory Medicine,

East Birmingham Hospital,

Birmingham B9 5ST

**We sent this letter to the manufacturers, who replied as follows.

EdITOR,-It is difficult to understand why Jon $G$ Ayres refers to Sergeant's Dust Mite Patrol specifically and not to any other product. If his argument is that acaricides designed for use against clinically important mites should be restricted in availability then he should lobby the Medicines Control Agency over its licensing of the product. On the other hand, he acknowledges that the 